\title{
Deliberações em nível federal e impactos sobre as finanças públicas do Rio Grande do Sul ${ }^{*}$
}

\author{
Deliberations at the Federal Level and Impacts on Public Finances in Rio \\ Grande do Sul
}

Jacó Braatz e Mariana Mariano da Rocha**

\begin{abstract}
Resumo: O presente artigo tem como objetivo demonstrar a influência das decisões tomadas em âmbito federal na deterioração das finanças públicas dos entes subnacionais. Analisa-se três temas e seus impactos: os parâmetros do FUNDEB, o Piso Nacional do Magistério e os efeitos da Lei Kandir nas receitas estaduais que afetam significativamente as finanças dos entes subnacionais, ameaçando o equilíbrio orçamentário, em especial dos estados, como será visto no caso do Rio Grande do Sul. Avalia-se, em síntese, que estas três circunstâncias, ainda que decididas majoritariamente no âmbito federal, têm implicações reais ou potenciais de grandes proporções para as finanças públicas do Rio Grande do Sul. Tomadas em absoluto e em seu conjunto, as grandezas envolvidas chegam a custar para as finanças estaduais uma média de $\mathrm{R} \$ 3,36$ bilhões anuais, cifra esta que corresponde a mais de 8\% da RCL anual do estado do Rio Grande do Sul.
\end{abstract}

Palavras-chave: Finanças públicas; Entes subnacionais; Impactos de decisões externas

Abstract: this article aims to demonstrate the influence of decisions taken at the federal level in the deterioration of public finances of subnational entities. Three themes and their impacts are analyzed: the parameters of FUNDEB, the National Teaching Floor and the effects of the Kandir Law on state revenues that significantly affect the finances of subnational entities, threatening the budget balance, especially in the states, as will be seen in the case of Rio Grande do Sul. It is estimated, in short, that these three circumstances, even though mostly decided at the federal level, have real or potential implications of great proportions for the public finances of Rio Grande do Sul. Taken together, the amounts involved cost the state finances an average of $\mathrm{R} \$ 3.36$ billion a year, a figure that corresponds to more than $8 \%$ of the annual RCL in the state of Rio Grande do Sul.

Keywords: Public finances; Subnational entities; Impacts of external decisions.

JEL: H29; H60; H72

\footnotetext{
* Submissão: 20/02/2020 | Aprovação: 13/09/2020 | DOI: 10.5380/re.v42i78.71837

** Respectivamente: (1) Auditor Fiscal do Tesouro Estadual da Secretaria da Fazenda do Estado do Rio Grande do Sul (SEFAZ-RS) | E-mail: jacobraatz@hotmail.com | ORCID: 0000-0002-5040-7859 | (2) Economista Estadual da Secretaria da Fazenda do Estado do Rio Grande do Sul (SEFAZ-RS) | E-mail: marianacrmrocha@gmail.com | ORCID: 0000-0002-7958-5683
} 


\section{Introdução}

Dentre a miríade de temáticas possíveis no campo do federalismo, o presente texto propõe-se à discussão de três temas que, tanto política quanto judicialmente, carecem de opinião consensual entre os níveis federal e estadual. São eles: os parâmetros do Fundo de Manutenção e Desenvolvimento da Educação Básica e de Valorização dos Profissionais da Educação (FUNDEB), o Piso Nacional do Magistério (PNM) e os efeitos da Lei Kandir nas receitas estaduais. Apesar desses temas serem de deliberação em nível federal, eles afetam significativamente as finanças dos entes subnacionais, ameaçando o equilíbrio orçamentário, em especial dos estados, como será visto no caso do Rio Grande do Sul.

A partir da análise desses aspectos e da explicitação da sua relevância para o Rio Grande do Sul, o presente artigo tem como objetivo demonstrar a influência das decisões tomadas em âmbito federal na deterioração das finanças públicas do estado. As circunstâncias que envolvem os temas propostos estão relacionadas aos termos do pacto federativo brasileiro e aos objetivos mais amplos das políticas públicas correspondentes, nos campos da educação e crescimento econômico. Envolvem, portanto, um conjunto de elementos tanto de natureza técnica como política, não sendo passíveis de análise a partir de analogias com empresas privadas que interagem no ambiente de mercado. Nesse contexto, torna-se inócuo atribuir a desordem das economias dos estados-federados a apenas decisões tomadas em âmbito estadual.

Com respeito ao FUNDEB, aponta-se que a combinação entre certas tendências demográficas e as regras relativas às contribuições e retorno dos recursos implicam em perdas significativas de recursos para o Rio Grande do Sul. Com respeito ao Piso Nacional do Magistério, discute-se que a sua implementação implicaria em um considerável impacto nas despesas com pessoal, entrando em contradição com a Lei de Responsabilidade Fiscal. Com relação à Lei Complementar 87/96, apuram-se os efeitos das desonerações tributárias às exportações na arrecadação estadual, agravados pela falta de compensação efetiva.

Avalia-se, em síntese, que essas três circunstâncias, ainda que decididas majoritariamente no âmbito federal, têm implicações reais ou potenciais de grandes proporções para as finanças públicas do Rio Grande do Sul. Tomadas em absoluto e em seu conjunto, as grandezas envolvidas chegam a custar para as finanças estaduais uma média de $\mathrm{R} \$ 3,36$ bilhões de reais anuais, cifra essa que 
corresponde a mais de 8\% da RCL (Receita Corrente Líquida) anual do Estado do Rio Grande do Sul.

Para atingir o objetivo proposto, além da Introdução, o presente artigo está organizado em 4 seções. A Seção 1 discorre sobre o FUNDEB e seu impacto nas finanças do estado gaúcho. Em seguida, a Seção 2 aborda as regras do Piso Nacional do Magistério e seu potencial conflitivo com as regras fiscais de gastos com pessoal para os estados. Na Seção 3, discute-se a Lei Kandir e seus desdobramentos recentes, com destaque para o recente acordo entre a União e os estados sobre repasses de compensação obrigatórios. A Seção 4 traz uma estimativa dos impactos orçamentários dos temas abordados para o período de 2010 a 2014. Por fim, apresentam-se as considerações finais sobre o presente trabalho, situando-o dentro das discussões sobre o saneamento das finanças estaduais, mas também sobre o equilíbrio do pacto federativo.

A situação fiscal dos entes subnacionais tem sido tema recorrente do debate público e, como tal, também objeto de ampla atenção dos órgãos oficiais. Documento recentemente produzido pela Secretaria do Tesouro Nacional (STN) busca discutir a possibilidade de fomentar aquelas que a instituição entende ser as "melhores práticas" relativas ao federalismo fiscal tendo em vista a manutenção da sustentabilidade fiscal e da estabilidade macroeconômica. Sugere-se no mesmo trabalho um conjunto de medidas que visam aproximar o atual arcabouço institucional daquelas práticas, empreendendo esforços para conter, por exemplo, aqueles que são referidos como "vazamentos da regulação" bem como para evitar o "excesso de judicialização" das questões que envolvem os passivos dos entes subnacionais e o cumprimento das obrigações decorrentes (STN, 2018).

A leitura do texto deixa clara a concepção de um comportamento considerado ideal para entes subnacionais, que poderia vir a ser induzido pelo marco institucional e jurídico apropriado. Para efetivamente promover esse comportamento, seria necessário submeter os agentes envolvidos a uma disciplina que leve em conta a existência de "falhas de mercado" na relação entre os entes federados, a União e fontes externas de financiamento. Menciona-se especificamente a possibilidade de haver componentes de "moral hazard" na referida relação. De um modo simples, tal situação de "risco moral" está relacionada a um contexto de assimetria de informações em que uma parte na transação tem incentivos ou tendência a agir inapropriadamente, conforme o 
interesse da outra parte. Trata-se de uma situação em que o assim chamado "agente" detém mais informações sobre suas ações ou intenções, quando comparado ao assim chamado "principal" da relação. Tal situação dá origem a resultados ineficientes e supostamente relacionados, de acordo com a perspectiva da STN, às questões envolvidas nas dificuldades financeiras da União e dos próprios entes.

Não se pretende aqui negar que os entes subnacionais de fato possam ter, em diferentes situações, mais informações sobre a sua própria situação financeira do que a própria União, e que tal circunstância possa influenciar certas decisões particulares. Mas parece importante ter extrema cautela com respeito à aplicação direta dos conceitos relacionados à informação assimétrica, concebidos originalmente para descrever o comportamento de agentes privados, na análise de questões ligadas ao federalismo fiscal e ao comportamento dos entes públicos subnacionais. Ter acesso à informação mais completa sobre determinada situação não equivale a ter, necessariamente, um grau considerável de controle sobre essa mesma situação. Uma aplicação acrítica do conceito econômico convencional de risco moral às relações entre os entes federados e a União pode facilmente conduzir à ideia errônea de que uma condição financeira desconfortável dos entes federados seja resultado exclusivo de suas próprias ações. Somente nesse caso a questão das finanças estaduais estaria resumida simplesmente a induzir um comportamento "adequado" aos entes subnacionais. Ainda que sempre se possa identificar decisões ao nível estadual que sejam passíveis de crítica segundo qualquer comportamento idealizado, também parece trivial estabelecer como premissa que a condição resultante das finanças estaduais não dependa apenas das ações dos próprios entes e/ou de governos específicos em mandato, como também de um ambiente jurídico, político e econômico mais amplo sobre o qual seu grau de controle é absolutamente reduzido.

Com respeito ao caso específico do Rio Grande do Sul, o levantamento feito por Petry et al. (2018) sobre um conjunto de medidas postuladas ou executadas para lidar com os problemas relativos às finanças estaduais mostra que as articulações em nível federal têm um efeito três vezes superior àquelas que dependem apenas de decisões a nível estadual. Como é de amplo conhecimento, o Estado do Rio Grande do Sul convive há um tempo já bastante longo com parcelamentos de salários e dificuldades diversas para cumprir seus compromissos. 
E tais dificuldades seriam certamente ainda piores não fossem as decisões recentes do STF que alteraram os termos do endividamento com a União e reduziram as despesas com os serviços relacionados.

Ainda que qualifique as decisões da suprema corte enquanto parte de um "excesso de judicialização", o texto referido da STN reconhece que o fundamento dessas decisões favoráveis aos entes subnacionais nas questões relativas ao endividamento tem sido a necessidade de garantir os recursos indispensáveis à manutenção dos serviços públicos essenciais (STN, 2018, p. 77). Isso significa que os tribunais superiores entendem que sob as circunstâncias colocadas é preciso evitar a descontinuidade de serviços públicos considerados essenciais, diante de uma situação financeira avaliada como bastante delicada. O texto da STN também reconhece que, ao contrário das empresas privadas que ao "quebrarem" simplesmente desaparecem do mercado, o mesmo não ocorre com as unidades da federação. Mesmo em condições financeiras adversas, tais unidades seguem "existindo e ofertando bens e serviços públicos com saúde, segurança, educação e investimento em infraestrutura" (STN, 2018, p. 55)

$\mathrm{Na}$ medida em que se leve esses pontos em consideração, parece claro que a questão das dificuldades fiscais dos entes federados é mais ampla do que poderia ser resolvido com uma indução a um comportamento idealmente virtuoso, especialmente se este é concebido no contexto do comportamento de agentes econômicos privados no mercado. O problema requer reflexão e reconsideração mais ampla sobre os parâmetros do federalismo fiscal no Brasil. O fato de que, aos dados parâmetros, muitos entes subnacionais enfrentem precárias condições financeiras não implica que deixarão de existir, nem que deixarão de ser responsáveis pela execução de certos serviços públicos considerados básicos e a eles atribuídos. Por outro lado, diversos parâmetros específicos que normatizam o cumprimento dos serviços básicos são majoritariamente definidos $\mathrm{e}$ frequentemente alterados de forma absolutamente exógena aos entes subnacionais. Em conjunto com o curso dos acontecimentos sociais e econômicos, determinados parâmetros e regras estabelecidos têm por consequência efeitos nada desprezíveis sobre as finanças estaduais. No texto que se segue, serão analisados três aspectos contemplados nesse contexto: as regras do FUNDEB, o Piso Nacional do Magistério e as implicações da Lei Kandir. 


\section{FUNDEB}

Nesta seção, analisa-se a distribuição dos recursos do Fundo de Manutenção e Desenvolvimento da Educação Básica e de Valorização dos Profissionais da Educação (FUNDEB), entre os entes federados. Depois de uma breve análise sobre a definição e as características do FUNDEB, são apresentados os efeitos das regras estabelecidas para o Rio Grande do Sul entre 2007 e 2018.

Criado pela Emenda Constitucional no 53/2006 e regulamentado pela Lei $n^{\circ}$ 11.494/2007, o FUNDEB tem previsão de vigência de 2007 a 2020, mas a proposta de emenda à Constituição (PEC) $n^{\circ} 15-\mathrm{A} / 2015$, em tramitação no Congresso Nacional, busca torná-lo um instrumento permanente de financiamento da educação básica pública ${ }^{1}$. O FUNDEB substituiu o Fundo de Manutenção e Desenvolvimento do Ensino Fundamental e de Valorização do Magistério (FUNDEF), que vigorou de 1998 a 2006.

O FUNDEB é um fundo especial, de natureza contábil e de âmbito estadual, formado por $20 \%$ das receitas de cada um dos seguintes tributos e transferências constitucionais: ICMS, ITCD, IPVA, IPI exportação, ITR municípios, FPE, FPM, restituições da Lei Kandir, bem como eventuais novos tributos criados pela União de competência estadual ou municipal. Além dessa previsão de receitas, o regramento estabelece também que a União deve complementar os recursos do FUNDEB dos entes federados em que o valor médio ponderado por aluno e por estado $^{2}$ não alcançar o mínimo definido pelo Ministério da Educação. No caso do RS, de 2007 a 2018, o valor médio sempre esteve acima desse valor mínimo e o estado não fez jus, portanto, ao complemento da União.

É importante enfatizar que todo o valor arrecadado para o FUNDEB do RS é dividido exclusivamente entre o governo do Estado e os municípios gaúchos, ainda que haja reorganização na distribuição dos recursos entre o estado e os municípios. A divisão dessas receitas é determinada pelo número de alunos matriculados no ensino básico nas redes públicas estadual e municipais.

\footnotetext{
${ }^{1}$ A PEC no 15-A/2015 foi apresentada ao plenário da Câmara dos Deputados em 7 de abril de 2015 e já tramitou por várias comissões dessa casa legislativa. Porém, com a nova legislatura, foi solicitado o seu desarquivamento. Em 27 de fevereiro de 2019, um ato do presidente da Câmara criou a "Comissão Especial" para proferir parecer sobre essa PEC.

${ }^{2}$ A lei do FUNDEB (Lei $n^{\circ} 11.494 / 2007$, no seu Art. 15, III) estabelece que o Poder Executivo federal publicará, até 31 de dezembro de cada exercício, para vigência no exercício subsequente, o valor anual mínimo por aluno definido nacionalmente. A publicação consta na Portaria Interministerial $n^{\circ} 07$, de 28 de dezembro de 2018.
} 
No cálculo da repartição, a definição do valor por aluno/ano considera diferentes ponderações para as etapas/modalidades, localização e outros desdobramentos da educação básica. A cada ano, as administrações dos estados, distrito federal e municípios informam os dados de matrícula do ensino básico da sua unidade federativa ao Ministério da Educação. Essas informações são usadas para o cálculo do retorno do FUNDEB de todos os meses do exercício financeiro seguinte.

A participação do estado do RS para a constituição das receitas do fundo variou de 63,8\% do total em 2007 para 64,6\% do total em 2018. De um total de $\mathrm{R} \$ 2,756$ bilhões em 2007, o estado do Rio Grande do Sul foi responsável por R \$ 1,759 bilhão dessas receitas, contra a soma de $\mathrm{R} \$ 997$ milhões a partir das prefeituras gaúchas. Em 2018, o estado contribuiu com $\mathrm{R} \$ 6,116$ bilhões, e os municípios do RS, com R \$ 3,347 bilhões, de um montante total de receitas de $\mathrm{R} \$$ 9,463 bilhões referentes ao FUNDEB.

Observando a questão pela perspectiva da diferença entre as contribuições para as receitas totais e os valores retornados ao estado do Rio Grande do Sul, denominado como perda do FUNDEB para o estado, percebe-se que essa magnitude cresceu de $16 \%$ da contribuição em 2007 para 26,7\% da contribuição em 2018. O aumento da perda do FUNDEB para o Rio Grande do Sul ocorreu em função de ter sido reduzido proporcionalmente a cada ano o montante de retorno para o estado. Em valores nominais, o retorno saiu de R \$ 1,478 bilhão em 2007 para $\mathrm{R} \$ 4,483$ bilhões em 2018, conforme mostram os números da Tabela 1 abaixo. Com esses movimentos, a perda em termos nominais passou de cerca de $\mathrm{R} \$ 281$ milhões em 2007 para $\mathrm{R}$ \$ 1,63 bilhão em 2018. 
Tabela 1 - Contribuição, retorno e perdas do FUNDEB do estado do RS (2007-2018)

\begin{tabular}{c|c|c|c|c} 
Ano & $\begin{array}{c}\text { Contribuição } \\
(\mathbf{C})\end{array}$ & $\begin{array}{c}\text { Retorno } \\
(\mathbf{R})\end{array}$ & $\begin{array}{c}\text { Perda } \\
(\mathbf{C}-\mathbf{R})\end{array}$ & Perda/Contribuição \\
\hline 2007 & 1.759 .082 .127 & 1.477 .685 .370 & 281.396 .758 & $16,0 \%$ \\
\hline 2008 & 2.427 .736 .896 & 2.128 .286 .736 & 299.450 .160 & $12,3 \%$ \\
\hline 2009 & 2.731 .925 .373 & 2.415 .909 .054 & 316.016 .319 & $11,6 \%$ \\
\hline 2010 & 3.210 .213 .623 & 2.717 .194 .043 & 493.019 .580 & $15,4 \%$ \\
\hline 2011 & 3.515 .669 .687 & 2.961 .018 .094 & 554.651 .593 & $15,8 \%$ \\
\hline 2012 & 3.777 .401 .976 & 3.117 .794 .566 & 659.607 .411 & $17,5 \%$ \\
\hline 2013 & 4.286 .961 .302 & 3.436 .017 .331 & 850.943 .971 & $19,8 \%$ \\
\hline 2014 & 4.621 .093 .672 & 3.712 .396 .440 & 908.697 .232 & $19,7 \%$ \\
\hline 2015 & 4.921 .571 .229 & 3.866 .108 .471 & 1.055 .462 .758 & $21,4 \%$ \\
\hline 2016 & 5.330 .590 .675 & 4.158 .145 .383 & 1.172 .445 .292 & $22,0 \%$ \\
\hline 2017 & 5.558 .716 .333 & 4.170 .397 .750 & 1.388 .318 .584 & $25,0 \%$ \\
\hline 2018 & 6.115 .793 .273 & 4.483 .027 .874 & 1.632 .765 .400 & $26,7 \%$ \\
\hline TOTAL & 48.256 .756 .166 & 38.643 .981 .112 & 9.612 .775 .054 & $19,92 \%$
\end{tabular}

Fonte: Tesouro Nacional (2019) e Ministério da Educação (2019).

A queda na participação do governo do Estado nas receitas do FUNDEB está intrinsecamente associada com a alteração da Lei de Diretrizes e Bases da Educação Nacional - LDB (Lei n ${ }^{\circ}$ 12.796/2013) -, que ampliou a faixa etária que define a obrigatoriedade e gratuidade da educação básica, deixando de ser entre os 6 e os 17 anos de idade e passando a ser entre os 4 e os 17 anos. De acordo com a LDB, cabe aos estados assegurar o ensino fundamental (EF, 6-14 anos) e oferecer, com prioridade, o ensino médio (EM, 15-17 anos) a todos que o demandarem. Aos municípios cabe oferecer o ensino infantil (EI, 0-5 anos) em creches e pré-escolas e, com prioridade, o EF.

Ao estabelecer objetivos e metas a serem atingidos por estados e municípios até 2024, o Plano Nacional de Educação - PNE (Lei no. 13.005/2014) - também tem influência sobre a distribuição de receitas do FUNDEB. São relevantes para o cálculo do retorno as metas do PNE referentes à universalização do EI na préescola, para as crianças de 4 a 5 anos de idade, como também as de ampliação da oferta em creches, visando atender no mínimo 50\% das crianças de até 3 anos até o final da vigência do plano. Tais diretrizes levaram ao crescimento de cerca de 41\% nas matrículas no EI nas escolas municipais gaúchos, partindo de 216.810 alunos em 2013 para 305.679 alunos em 2018. 
Também consta no PNE a universalização das matrículas nas faixas etárias de 6 a 14 anos (período regulamentar do EF) e de 15 a 17 anos (período regulamentar do EM). Ainda considerando o período de 2013 a 2018, as matrículas no EF, compartilhadas entre as prefeituras e o setor público estadual, reduziram-se quase $12 \%$ na rede estadual e cresceram apenas $0,5 \%$ nas redes municipais. Já as matrículas no EM na rede pública estadual, responsável por cerca de $85 \%$ do total de alunos no RS nessa etapa de ensino no RS, reduziram-se $17,5 \%$ no período. As redes municipais tiveram apenas cerca de $1 \%$ dos alunos do EM, entretanto as matrículas desses alunos não pontuam para o cálculo do retorno do FUNDEB das prefeituras.

Considerando-se a continuidade da tendência de queda das matrículas na rede pública estadual e o seu aumento nas redes municipais, causadas sobretudo pela mudança demográfica que hoje caracteriza especialmente o Rio Grande do Sul, pode-se projetar uma continuidade da tendência até então verificada. Em função das quedas acentuadas nas taxas de natalidade, pode-se projetar que as perdas do RS em relação à sua contribuição para a formação das receitas do fundo se elevem para cerca de 32\%, em 2025 (PICOLOTTO, 2019). Para o ano de 2019, a projeção de perda com o FUNDEB é de R \$ 1,8 bilhão para o RS, representando cerca de $29 \%$ em relação à contribuição do governo estadual.

Alternativas que poderiam amenizar as perdas para o Rio Grande do Sul estariam em estabelecer medidas que aumentassem as matrículas do EM na rede pública estadual (dos jovens gaúchos entre 15 e 17 anos, apenas 56\% estavam matriculados nessa etapa de ensino nos últimos anos) e/ou alterações na legislação que elevem a participação das receitas federais. Deve-se observar por fim que a própria continuidade do FUNDEB está em discussão no Congresso Nacional (PEC $n^{\text {o }}$ 15-A/2015) e a manutenção ou a alteração das regras atuais dependerá naturalmente das negociações entre os poderes e os entes federados. Espera-se ter deixado claro, de todo modo, que os parâmetros gerais da política educacional que regem a distribuição dos recursos do FUNDEB, em conjunto com efeitos demográficos específicos, constituem um exemplo de circunstância que está completamente fora da esfera de deliberação estadual e que afeta de forma significativa as finanças públicas do Rio Grande do Sul. 


\section{Piso nacional do magistério}

Nesta seção, analisa-se um segundo aspecto relacionado ao campo da educação que tem importância central no que diz respeito às despesas dos entes subnacionais, que é o Piso Nacional do Magistério (PNM). São expostas algumas informações sobre a legislação que o define e os debates subsequentes, para em seguida apontar os conflitos envolvidos na sua efetiva implementação.

O PNM, de previsão constitucional, abrange todos os profissionais do magistério público da educação básica brasileira. O PNM foi instituído com a Lei $\mathrm{n}^{\mathrm{o}} 11.738$, de 16 de julho de 2008 , que estabeleceu um piso salarial inicial de $\mathrm{R} \$$ 950,00 , a ser atualizado a partir de $1^{\circ}$ de janeiro de $2010^{3}$ para os profissionais do magistério com formação em nível médio, na modalidade Normal, para a jornada de 40 (quarenta) horas semanais.

Art. $2^{\circ} \mathrm{O}$ piso salarial profissional nacional para os profissionais do magistério público da educação básica será de $\mathrm{R} \$$ 950,00 (novecentos e cinquenta reais) mensais, para a formação em nível médio, na modalidade Normal, prevista no art. 62 da Lei no 9.394, de 20 de dezembro de 1996, que estabelece as diretrizes e bases da educação nacional.

Pela norma, os profissionais com jornadas de trabalho diferentes de 40 horas devem ser pagos tendo como base o valor do piso salarial definido em lei, observando-se a carga de trabalho proporcional ${ }^{4}$. Para os profissionais com formação em nível superior, é necessário que os Estados e Municípios observem o estabelecido em suas próprias leis em relação à diferenciação salarial uma vez que, ao estabelecer apenas um piso, não fixa valor para os profissionais com nível superior. Como as remunerações para os profissionais de nível superior são estabelecidas em patamares maiores do que o piso, na prática este acaba afetando apenas os profissionais de nível médio.

O valor do piso também é estendido a todas as aposentadorias e pensões dos profissionais do magistério público da educação básica que sejam reajustadas pela paridade. Assim, o reajuste dos proventos é realizado na mesma proporção e na mesma data sempre que a remuneração dos servidores em atividade for

\footnotetext{
${ }^{3}$ Conforme Nota AGU/SGCT/MAS/No 110/2009.

${ }^{4}$ Artigo $2^{\circ}, \S 3^{\circ}$, da Lei no $11.738 / 2008$.
} 
modificada, inclusive quando decorrentes da transformação ou reclassificação do cargo ou função em que se deu a aposentadoria ${ }^{5}$.

Na Lei $n^{\circ}$. 11.738/2008, o piso salarial corresponde ao vencimento inicial da carreira. A própria lei federal permitiu considerar, entretanto, para o exercício de 2009, que o piso deveria ser respeitado considerando-se os vencimentos recebidos pelos profissionais, com as vantagens pecuniárias já inclusas ${ }^{6}$. A partir de 2010, passaria a ser considerado apenas o vencimento inicial, sendo este, portanto, necessariamente superior ao piso e sobre o qual seriam acrescidas as vantagens pecuniárias. Tal conceito foi alterado, entretanto, por força de uma medida cautelar concedida pelo Supremo Tribunal Federal (STF) ao analisar a Ação Direta de Inconstitucionalidade (ADI 4.167) ${ }^{7}$. A interpretação do $\S 1^{\circ}$ do artigo $2^{\circ}$ da Lei do Piso foi que o piso salarial seria o valor abaixo do qual a União, os Estados, o Distrito Federal e os Municípios não poderão praticar a remuneração dos professores, semelhante ao que era previsto para o exercício de 2009. Conforme observaremos à frente, tal interpretação tem consequências extremamente relevantes para a magnitude do impacto da legislação sobre as despesas efetivas.

Com respeito à questão da atualização do valor do piso, a Lei $\mathrm{n}^{\mathbf{o}}$ 11.738/2008 estabelece que deva ser atualizado anualmente com base no percentual de crescimento do valor mínimo nacional por aluno/ano do FUNDEB, referente aos anos iniciais do ensino fundamental urbano ${ }^{8}$. Esse valor é publicado anualmente pelo MEC, sendo afetado por estimativas que podem variar ao longo do ano, face à oscilação da arrecadação. Tal mecanismo de revisão definido pela lei é motivo de grande preocupação com respeito às finanças estaduais, pois a sua efetiva implementação determina cálculos salariais baseados em critérios bastante instáveis. A Tabela 2 mostra a evolução do PNM desde sua criação, a variação do valor pelo FUNDEB e a variação do INPC e IPCA no período.

\footnotetext{
${ }^{5}$ Art. $2^{\circ}, \S 5^{\circ}$ da Lei do Piso c/c Art. $7^{\circ}$ da Emenda Constitucional no 41/2003 e Emenda Constitucional no $47 / 2005$

${ }^{6}$ Artigo $3^{\circ}, \S 2$ da Lei do Piso.

7 A ADI nº 4.167 questiona alguns dispositivos da Lei Federal 11.738/2008 e foi ajuizado pelos governadores do Rio Grande do Sul, Santa Catarina, Paraná, Mato Grosso do Sul e Ceará.

${ }^{8}$ Artigo $5^{\circ}$. da Lei $n^{\circ}$. 11.738/2008.
} 
Tabela 2 - Crescimento do piso nacional do magistério e inflação (2009-2018)

\begin{tabular}{crrrr}
\hline ANO & \multicolumn{2}{c}{ PISO } & \multicolumn{1}{c}{ INPC } & \multicolumn{1}{c}{ IPCA } \\
\hline 2009 & Valor nominal & Reajuste & \multicolumn{1}{c}{ Variação } & Variação \\
2010 & 950,00 & - & $4,11 \%$ & $4,31 \%$ \\
2011 & $1.024,67$ & $7,86 \%$ & $6,47 \%$ & $5,91 \%$ \\
2012 & $1.187,08$ & $15,85 \%$ & $6,08 \%$ & $6,50 \%$ \\
2013 & $1.451,00$ & $22,23 \%$ & $6,20 \%$ & $5,84 \%$ \\
2014 & $1.567,00$ & $7,99 \%$ & $5,56 \%$ & $5,91 \%$ \\
2015 & $1.697,00$ & $8,30 \%$ & $6,23 \%$ & $6,41 \%$ \\
2016 & $1.917,78$ & $13,01 \%$ & $11,28 \%$ & $10,67 \%$ \\
2017 & $2.135,64$ & $11,36 \%$ & $6,58 \%$ & $6,29 \%$ \\
2018 & $2.298,80$ & $7,64 \%$ & $2,07 \%$ & $2,95 \%$ \\
Acumulado & $2.455,35$ & $6,81 \%$ & $3,43 \%$ & $3,75 \%$ \\
\hline
\end{tabular}

Fonte: Ministério da Educação (2019) e IBGE (2019).

Ocorre que tem sido observada uma tendência de redução do número de alunos no ensino fundamental, ao passo que as receitas do FUNDEB aumentaram ao longo do tempo. Com o cálculo do PNM sendo em função da razão entre a receita do FUNDEB e o número de matrículas, o aumento do PNM acaba resultando mais do que proporcional ao crescimento das receitas e constitui elevação da proporção das receitas potencialmente absorvidas pelos salários do magistério.

A lei estabelece que, nos casos em que Estados e Municípios não tenham disponibilidade financeira para cumprir o valor fixado, a União complemente a integralização do valor do piso. Entretanto, as várias exigências estabelecidas para a apresentação do pedido de complementação na prática inviabilizam a complementação da União com respeito ao estado do RS. A lei define que a fonte de recursos da União para a assistência financeira ao piso seja proveniente do limite de $10 \%$ dos recursos que a União colocará no FUNDEB, a título de complementação ${ }^{9}$. Se a assistência financeira da União fosse destinada para todos os nove Estados que recebem a complementação no FUNDEB, ainda assim, teríamos $3.808(68,5 \%)$ Municípios de 17 Estados sem esse aporte de recursos (CNM, 2011).

\footnotetext{
9 Pelas regras definidas na Lei do Piso (Art. $4^{\circ}$ ), apenas os Estados e os Municípios que recebem a complementação da União ao FUNDEB poderão apresentar o pedido de recursos complementares. Em 2010 e 2011, foram beneficiados os Estados de Alagoas, Amazonas, Bahia, Ceará, Maranhão, Pará, Paraíba, Pernambuco e Piauí.
} 
No caso específico do Rio Grande do Sul, o impacto da efetivação do PNM sobre a folha de pessoal tende a ser de grande magnitude, no caso de interpretarse o piso como valor mínimo para os vencimentos básicos. Estima-se que, assumindo-se essa interpretação, as despesas seriam acrescidas em cerca de $\mathrm{R} \$ 5,3$ bilhões, o que significa dobrar a folha salarial do magistério e elevar em torno de 17\% a despesa total com pessoal prevista para R\$ 31,2 bilhões em 2019. Concretamente, entretanto, o RS vem realizando os pagamentos de modo a evitar que a remuneração - acrescida de vantagens pecuniárias - seja inferior ao piso. Tal prática também implica em despesas adicionais em comparação aos vencimentos que seriam pagos na ausência da lei do piso. Conforme se pode observar na Tabela 3, entretanto, a magnitude da assim chamada Parcela Completiva decorrente do PNM é bastante inferior, ao que resultaria se o piso fosse aplicado aos vencimentos básicos, e pequena, ainda que crescente, como percentual da Receita Líquida de Impostos e Transferências (RLIT).

Tabela 3 - Parcela completiva do magistério (2012-18)

\begin{tabular}{cccccccc}
\hline & $\mathbf{2 0 1 2}$ & $\mathbf{2 0 1 3}$ & $\mathbf{2 0 1 4}$ & $\mathbf{2 0 1 5}$ & $\mathbf{2 0 1 6}$ & $\mathbf{2 0 1 7}$ & $\mathbf{2 0 1 8}$ \\
\hline R\$ mil & 68.685 & 85.164 & 77.603 & 82.547 & 129.844 & 162.512 & 226.278 \\
\hline \% RLIT & $0,34 \%$ & $0,37 \%$ & $0,31 \%$ & $0,31 \%$ & $0,45 \%$ & $0,53 \%$ & $0,67 \%$ \\
\hline
\end{tabular}

Fonte: Secretaria da Fazenda do Rio Grande do Sul.

Independentemente de qualquer avaliação sobre a maior ou menor necessidade de elevar a remuneração dos professores, o que se quer aqui chamar a atenção é para a relevância e os conflitos envolvidos no que diz respeito a essa legislação. De um lado, pode-se argumentar que o Rio Grande do Sul não vem cumprindo a legislação referente ao PNM e nesse sentido já acumula passivos contingentes da ordem de R $\$ 30$ bilhões. De outro, o efetivo cumprimento da norma do PNM implicaria ultrapassar os limites estabelecidos na Lei de Responsabilidade Fiscal, fato que em tese gera risco de intervenção federal e responsabilização por improbidade administrativa. Parece explícito, desse modo, o conflito entre diferentes regramentos aos quais estão sujeitos os gestores estaduais. Portanto, mais do que algo que possa ser atribuído a qualquer julgamento de parte dos gestores estaduais, pretende-se aqui ressaltar esse duplo aspecto que envolve não só a exogeneidade como a contradição entre os regramentos. Ao propor via Lei Federal, sem qualquer previsão nas Leis 
Orçamentárias Estaduais, um piso que fixa vencimentos de uma carreira fundamental para as condições estaduais ${ }^{10}$ e municipais, fica bastante claro que há um evento exógeno que se sobrepõe à esfera de deliberação estadual e que estabelece uma situação de descumprimento de uma segunda regra, a LRF. Além dos conflitos legais entre diferentes normas estabelecidas, há também uma série de deliberações específicas a nível técnico, jurídico e político que tornam algo instável o próprio valor do piso ao longo dos anos, afetando de um modo geral um efetivo controle das finanças estaduais.

\section{Lei complementar 87/1996 ("Lei Kandir")}

Nesta seção, será abordada a Lei Complementar n 87/1996, conhecida como Lei Kandir, que se destinou a regular a previsão constitucional de desoneração às exportações de produtos primários e semimanufaturados, complementando a já existente imunidade tributária com relação à exportação de bens industrializados.

A Lei Complementar $n^{\circ} 87$ de 13 de setembro de 1996, com vigência a partir de 01 de novembro do mesmo ano, trouxe para os estados brasileiros a desoneração das exportações de produtos primários e semielaborados em relação ao principal imposto estadual, o ICMS ${ }^{11}$.

A motivação por trás da lei, de caráter federal, era o aumento de competitividade das exportações brasileiras no mercado internacional e melhorar a balança comercial brasileira. Desde a implementação do Plano Real, em 1994, o país vinha apresentando crescentes déficits comerciais, dado o uso do câmbio apreciado como âncora nominal. A desoneração das exportações seria, portanto, uma forma de "desvalorização fiscal", haja vista a impossibilidade de manipulações no câmbio.

No entanto, desde o início de sua vigência, a Lei Kandir foi percebida como um problema adicional às finanças estaduais, sobretudo aos estados mais dependentes de renda de exportações. No caso do Rio Grande do Sul, por exemplo, o ICMS representava, na época, em torno de $65 \%$ das receitas correntes do estado. Os estados defendiam que, com as desonerações, a queda esperada nas receitas

\footnotetext{
${ }^{10}$ A carreira do magistério no Rio Grande do Sul constitui $66 \%$ do total de vínculos do Poder Executivo (Boletim Informativo de Pessoal, dezembro de 2018, página 11).

${ }^{11}$ Por meio da Emenda Constitucional no 42 de 19 de dezembro de 2003, a CF/1988 passou a dar imunidade total às exportações, fossem elas de mercadorias ou de serviços.
} 
fosse mais prejudicial e direta do que um aumento no volume exportado e seu efeito transbordo sobre o crescimento econômico e, consequentemente, sobre a arrecadação tributária.

Muitas das críticas eram também direcionadas ao caráter potencialmente inconstitucional da LC no 87/1996. Ainda que a União detenha competência privativa para regulamentar a atividade de comércio exterior, entende-se que a competência tributária é concorrente entre os entes federados e, portanto, cada ente detém o poder de tributar no âmbito de seus interesses (art. 24, I, CF/1988). Especificamente no caso do imposto sobre consumo de mercadorias e serviços (ICMS), ele é de competência estadual e cada estado tem certa margem de discricionariedade para decidir sobre as alíquotas de cada categoria de produtos. Portanto, na medida em que a LC no 87/1996 promovia alterações a um imposto de competência estadual, o qual apenas as Assembleias estaduais teriam competência para fazê-lo, entendia-se que isso feria o pacto federativo.

Como mecanismo de compensação de perdas aos estados, a própria LC $\mathrm{n}^{\circ}$ 87/1996 previu o chamado "seguro-receita", que buscava compensar uma possível queda real nas arrecadações em virtude das alterações introduzidas pela referida Lei por meio de repasses mensais de recursos pela União. Referido dispositivo, que sofreu alterações e foi estendido até 2006, manteve um caráter temporário e um limite global máximo para os valores anuais repassados. Prevalecia o entendimento da União, de que os impactos negativos sobre a arrecadação seriam eventualmente compensados pelo efeito multiplicador da lei e da ampliação da base tributária do ICMS.

Em 2003, por meio da Emenda Complementar $n^{\circ} 42^{12}$, as disposições da LC $n^{\circ} 87 / 1996$ foram constitucionalizadas e todas as exportações brasileiras, tanto de bens como de serviços, passaram a ser imunes de impostos. A EC 42/2003 também trouxe ao patamar constitucional o mecanismo de compensação da Lei Kandir por meio da introdução do artigo 91 ao Ato das Disposições Constitucionais Transitórias $(\mathrm{ADCT})^{13}$. O montante a ser repassado, no entanto, seria definido por lei complementar, o que nunca ocorreu até o presente.

\footnotetext{
${ }^{12}$ Art. 155, X, a: o ICMS não incidirá, 'sobre operações que destinem mercadorias para o exterior, nem sobre serviços prestados a destinatários no exterior, assegurada a manutenção e o aproveitamento do montante do imposto cobrado nas operações e prestações anteriores; $\left(E C n^{\circ} 42\right.$, de 19.12.2003)

${ }^{13}$ Art. 91. A União entregará aos Estados e ao Distrito Federal o montante definido em lei complementar, de acordo com critérios, prazos e condições nela determinados, podendo considerar as exportações para o exterior de produtos primários e semielaborados, a relação entre as exportações e as importações, os créditos
} 
Como decorrência das negociações que antecederam a aprovação da EC 42/2003, também foi criado, em 2004, o Auxílio Financeiro à Exportação (FEX), voltado para a compensação exclusivamente das imunidades tributárias incidentes aos bens primários e semielaborados ${ }^{14}$.

\subsection{Revisão bibliográfica sobre os efeitos da Lei Kandir sobre os estados}

Desde a criação da lei, inúmeros estudos buscaram verificar os efeitos da Lei Kandir sobre as finanças dos estados. A literatura disponível é dúbia em relação aos efeitos reais das medidas impostas pela LC n⿳ 87/1996, mas é majoritária no sentido de apontar a existência efetiva de perdas na arrecadação dos estados federados.

Kume e Piani (1997) estimaram as alíquotas médias de ICMS sobre as exportações por estado e as receitas que deixariam de ser auferidas via tributação às vendas externas com base nos anos 1994 e 1995. Os resultados mostraram alíquota média para o Brasil de 5,7\% em 1994 e 5,2\% em 1995 e perdas arrecadatórias de US\$ 1,308 bilhões e US\$ 1,326 bilhões ${ }^{15}$. Para o Rio Grande do Sul, os autores estimaram alíquotas de $6,5 \%$ e 5,8\% e perdas de US\$ 155,5 e US\$ 156,7 milhões para os anos de 1997 e 1998, respectivamente.

Os mesmos autores também calcularam o possível ganho em termos de aumento de exportações para o país, dado o efeito trazido pela lei. Supondo elasticidade-preço da oferta de exportações de 2, próximo à média das exportações brasileiras, o resultado foi de um ganho no saldo comercial de US\$2,519 bilhões,

decorrentes de aquisições destinadas ao ativo permanente e a efetiva manutenção e aproveitamento do crédito do imposto a que se refere o art. $155, \S 2^{\circ}, X$, a.

$\S 1^{\circ}$ Do montante de recursos que cabe a cada Estado, setenta e cinco por cento pertencem ao próprio Estado, e vinte e cinco por cento, aos seus Municípios, distribuídos segundo os critérios a que se refere o art. 158, parágrafo único, da Constituição.

$\S 2^{\circ}$ A entrega de recursos prevista neste artigo perdurará, conforme definido em lei complementar, até que o imposto a que se refere o art. 155, II, tenha o produto de sua arrecadação destinado predominantemente, em proporção não inferior a oitenta por cento, ao Estado onde ocorrer o consumo das mercadorias, bens ou serviços. $\S 3^{\circ}$ Enquanto não for editada a lei complementar de que trata o caput, em substituição ao sistema de entrega de recursos nele previsto, permanecerá vigente o sistema de entrega de recursos previsto no art. 31 e Anexo da Lei Complementar $n^{\circ}$ 87, de 13 de setembro de 1996, com a redação dada pela Lei Complementar $n^{\circ} 115$, de 26 de dezembro de 2002.

$\S 4^{\circ}$ Os Estados e o Distrito Federal deverão apresentar à União, nos termos das instruções baixadas pelo Ministério da Fazenda, as informações relativas ao imposto de que trata o art. 155, II, declaradas pelos contribuintes que realizarem operações ou prestações com destino ao exterior.

${ }^{14}$ Em consonância com a constitucionalização dos mecanismos de repasse e auxílio para a exportação de bens primários e semielaborados, também foi criado o Fundo de Compensação pela Exportação de Produtos Industrializados (FPEX), que não deve ser confundido com o auxílio federal associado à Lei Kandir.

15 Taxa de câmbio média do período em 1994, R\$ 0,63 R\$/US\$ e em 1995, R\$ 0,96 R\$/US\$. 
frente a uma perda arrecadatória dos estados de aproximadamente US\$ 1,3 bilhão ${ }^{16}$. Os autores ainda demonstram que esses resultados são agregados para o Brasil, podendo ser assimetricamente distribuídos para estados mais intensivos em exportações, como Pará e Minas Gerais, por exemplo.

Versano (2013), ainda que reconheça ser impossível uma quantificação razoavelmente precisa das variações de receita atribuíveis às alterações introduzidas pela LC n 87/1996, advoga que, no médio prazo, as perdas de arrecadação dos estados seriam compensadas por efeitos positivos do fim da dupla tributação de insumos para a produção sobre as receitas. O autor estima que, ao final de 2000, o valor real das entregas de recursos feitas desde outubro de 1996 ao conjunto dos estados superou as perdas de arrecadação nas exportações acumuladas durante o período ${ }^{17}$. À exceção de Amazonas e Maranhão, todos os demais estados apresentaram crescimento médio da arrecadação acima do crescimento do PIB entre 1997 e 2000.

Há diversos trabalhos avaliando o impacto das desonerações para estados brasileiros em específico. Para o Rio Grande do Sul, há cinco trabalhos voltados para apurar as perdas causadas pelas desonerações das exportações pela Lei Kandir ou para discutir essas perdas. Bósio (1999), reproduzindo os cálculos efetuados por Bordin (1997 apud Bósio, 1999), afirma que as perdas com a Lei Kandir para o estado são superiores a R\$ 600 milhões para os anos de 1997 e 1998, com base nos valores de ICMS apurados em 1995.

Frizzo (2008) faz uma análise dos efeitos da Lei Kandir na arrecadação do RS entre 1998 e 2005, com o uso de 'método estatístico comparativo', que seria uma espécie de médias históricas de arrecadação e desoneração fiscal do ICMS, antes e depois da Lei. Por esse método, a desoneração média estimada antes de 1997 era de 30,51\% e subiu para 36\% após 1997. Assim, o autor chega à conclusão de que o RS contabilizou perdas reais de $\mathrm{R} \$ 3,19$ bilhões no período.

Santos (2018) apresenta argumentos que, segundo o autor, comprovam que as perdas da Lei Kandir só existiriam no triênio ou quadriênio seguinte ao início

\footnotetext{
${ }^{16}$ Os dados da arrecadação do ICMS para o Brasil (IPEA, 2018) mostram que o modelo proposto pelos autores superestimou a perda para 1997, $\mathrm{R} \$ 1,023$ bilhões em valores de 1997 e subestimou a perda para 1998, R \$ 2,167 bilhões em valores de 1997. Em 1999, já não havia mais perdas de arrecadação. Ver tabela 3 no apêndice.

${ }^{17}$ Sem, contudo, serem avaliadas as compensações devidas à desoneração dos bens de capital e material de consumo.
} 
de sua vigência, porque a razão ICMS/PIB caiu nesse período. Após 2000 ela passou a ser maior que nos anos de 1995 e 1996, como se observa na Figura 2.

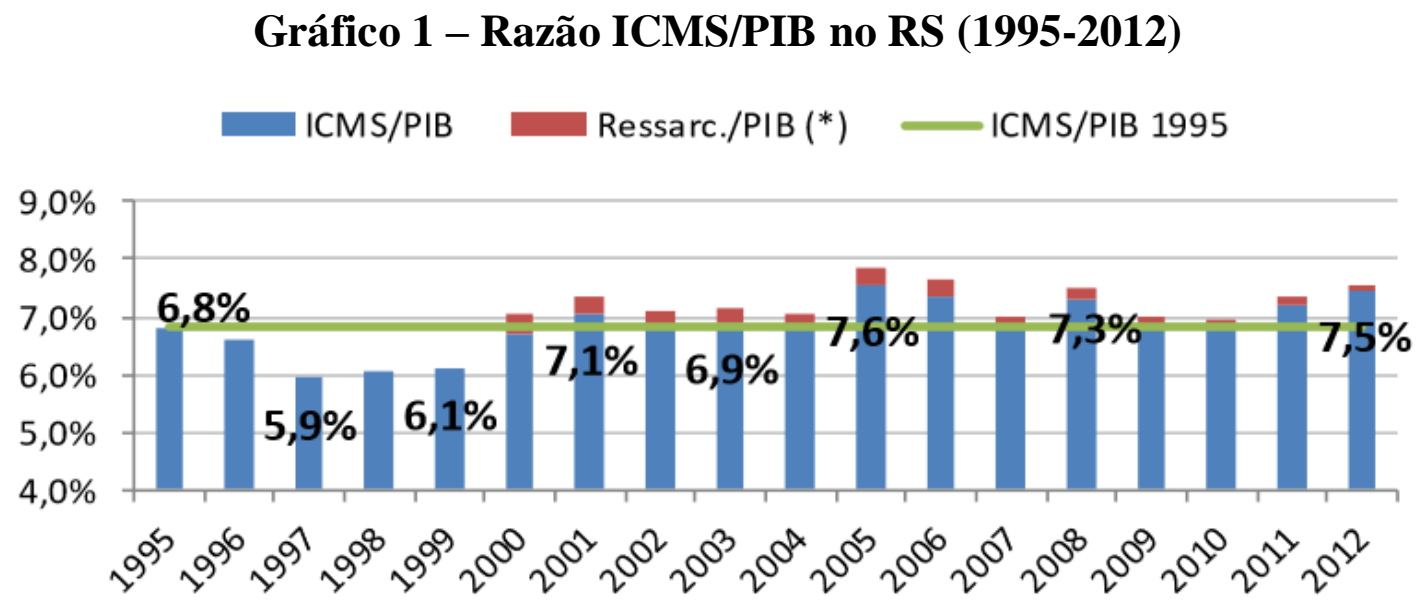

Fonte: Santos (2018).

Soccoloski e Montoya (2018) apuraram os valores das perdas decorrentes da LC $n^{\circ}$ 87/1996 especificamente das desonerações de exportações de café realizadas pelos municípios que compõem o Conselho Regional de Desenvolvimento da região da Produção (Corede Produção) no RS. Os resultados obtidos demonstraram que, das perdas líquidas do RS com as desonerações entre 1997 e 2014, mais de 16\% foram referentes à exportação de soja do Corede.

Uma análise histórica mais abrangente das perdas relativas associadas à Lei Kandir foi realizada pela Secretaria da Fazenda do Rio Grande do Sul em documento intitulado "Demonstrativo das Desonerações Fiscais do RS" (2015), utilizando a metodologia da COTEPE/CONFAZ para cálculo de perdas decorrentes das desonerações fiscais. Na seção voltada para uma análise específica da Lei Kandir, foram consideradas apenas as perdas relacionadas às desonerações aplicadas a exportações de produtos primários e semielaborados e dos bens de ativo fixo.

A Tabela 4 traz as perdas líquidas calculadas com as desonerações a partir da vigência da LC ñ 87/1996 para o período de 1996 a 2014, isto é, as perdas brutas de arrecadação descontadas das compensações do "seguro-receita" e, a partir de 2004, do Fundo de Compensação pela Exportação de Produtos Industrializados (Fex). 
Tabela 4 - Perdas e compensações decorrentes da LC 87/96 para o RS, 1996-2014 (valores nominais)

\begin{tabular}{rrrrr}
\hline Ano & Perdas brutas ${ }^{18}$ & $\begin{array}{c}\text { Compensações } \\
\text { totais }{ }^{19}\end{array}$ & \multicolumn{1}{c}{$\begin{array}{c}\text { Perdas } \\
\text { Líquidas }\end{array}$} & $\begin{array}{c}\text { Compensação } \\
\text { /Perdas } \\
\text { brutas }\end{array}$ \\
\hline 1996 & 68.033 .989 & 43.562 .897 & 24.471 .092 & $64,0 \%$ \\
\hline 1997 & 452.634 .699 & 40.800 .067 & 411.834 .632 & $9,0 \%$ \\
\hline 1998 & 528.156 .735 & 419.884 .722 & 108.272 .013 & $79,5 \%$ \\
\hline 1999 & 584.734 .753 & 345.849 .573 & 238.885 .180 & $59,1 \%$ \\
\hline 2000 & 707.335 .585 & 388.662 .178 & 318.673 .407 & $54,9 \%$ \\
\hline 2001 & 537.787 .519 & 359.740 .286 & 178.047 .233 & $66,9 \%$ \\
\hline 2002 & 959.954 .756 & 397.020 .219 & 562.934 .537 & $41,4 \%$ \\
\hline 2003 & 1.357 .286 .912 & 426.121 .157 & 931.165 .755 & $31,4 \%$ \\
\hline 2004 & 1.409 .305 .729 & 409.128 .640 & 1.000 .177 .089 & $29,0 \%$ \\
\hline 2005 & 1.180 .959 .683 & 450.288 .790 & 730.670 .893 & $38,1 \%$ \\
\hline 2006 & 1.331 .757 .120 & 399.459 .195 & 932.297 .925 & $30,0 \%$ \\
\hline 2007 & 1.741 .289 .090 & 358.299 .045 & 1.382 .990 .045 & $20,6 \%$ \\
\hline 2008 & 2.125 .061 .443 & 427.292 .450 & 1.697 .768 .993 & $20,1 \%$ \\
\hline 2009 & 2.166 .081 .842 & 374.290 .605 & 1.791 .791 .237 & $17,3 \%$ \\
\hline 2010 & 2.176 .722 .775 & 352.642 .875 & 1.824 .079 .900 & $16,2 \%$ \\
\hline 2011 & 2.640 .506 .515 & 345.556 .965 & 2.294 .949 .550 & $13,1 \%$ \\
\hline 2012 & 2.915 .677 .559 & 323.318 .580 & 2.592 .358 .979 & $11,1 \%$ \\
\hline 2013 & 3.311 .013 .788 & 345.546 .825 & 2.965 .466 .963 & $10,4 \%$ \\
\hline 2014 & 3.692 .401 .753 & 346.447 .140 & 3.345 .954 .613 & $9,4 \%$ \\
\hline TOTAL & 29.886 .702 .245 & 6.553 .912 .209 & 23.332 .790 .036 & $21,9 \%$ \\
\hline
\end{tabular}

Fonte: SEFAZ (2015), dados brutos DEE e COTEPE/CONFAZ.

O documento concluiu que as medidas de compensação nunca compensaram integralmente as perdas dos estados com as desonerações. Em valores correntes, calculou-se uma perda líquida acumulada pelo RS de R \$23,3 bilhões para o período de 1996-2014, sendo a perda bruta equivalente a $\mathrm{R} \$ 29,9$ bilhões. Como demonstrado no Gráfico 2, o percentual de compensação pela União aos estados nunca foi integral e foi diminuindo ao longo do tempo, já que as perdas brutas calculadas aumentaram.

\footnotetext{
18 Referentes às desonerações das exportações de bens do ativo fixo, iniciada em setembro de 2006, e de produtos primários e semielaborados, iniciada em janeiro de 1997.

${ }^{19}$ Referentes tanto ao mecanismo de "seguro-receita", criado pela LC 87/96, quanto pelo FEX, a partir de 2004.
} 


\section{Gráfico 2 - Evolução das perdas e compensações decorrentes da LC 87/96} para o RS, 1996-2014 (valores nominais)

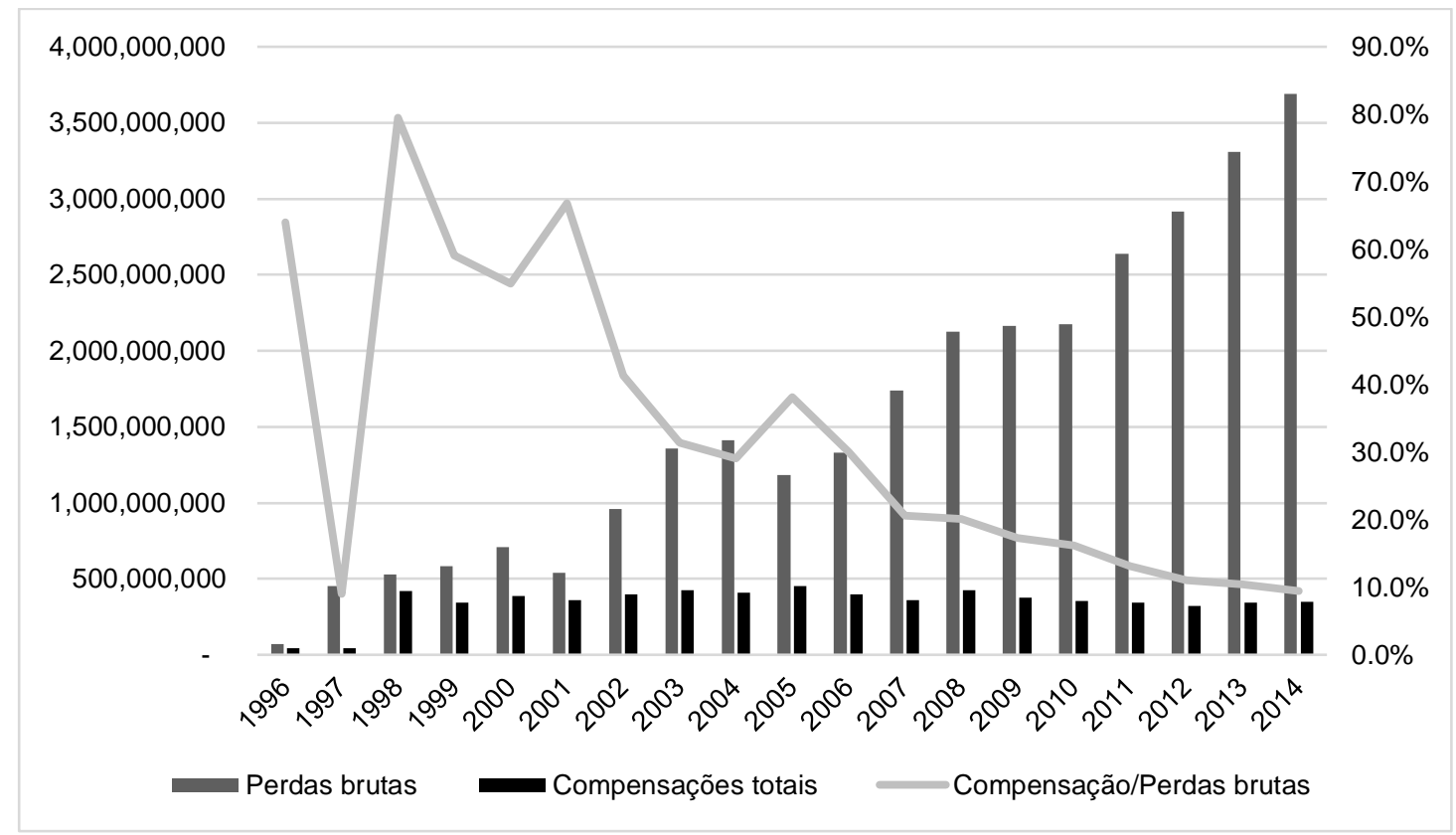

Fonte: SEFAZ (2015), dados brutos DEE e COTEPE/CONFAZ, elaboração própria dos autores.

\subsection{Desdobramentos recentes acerca da Lei Kandir}

Em 2013, o estado do Pará entrou com uma Ação Direta de Omissão (ADO 25), junto ao STF, apontando a necessidade de lei complementar que regulamentasse o mecanismo de compensação de perdas da Lei Kandir, conforme previsto constitucionalmente desde a EC 42/2003. Em 2016, a ADO 25 foi julgada procedente e foram reconhecidos, além dos prejuízos aos Estados, os danos ao equilíbrio do pacto federativo decorrentes da ausência do mecanismo. Como consequência da decisão, o Congresso Nacional foi instado a editar uma lei complementar sobre o tema no prazo de 12 meses $^{20}$. Contudo, o mesmo não ocorreu, e os repasses compensatórios da União permanecem interrompidos desde 2017.

No dia 13 de maio de 2020, os governadores de todos os 27 estados anunciaram formalmente sua anuência a um acordo com a União, mediado pelo STF, que busca solucionar o impasse das compensações e preencher a lacuna legislativa existente com a não regulamentação do artigo 91 da ADCT. Conforme

\footnotetext{
${ }^{20}$ Como forma de assegurar o enforcement da decisão, o Ministro Relator da ADO 25 definiu que, até a edição da lei complementar que regulamente o artigo 91 do ADCT, a definição do montante a ser anualmente transferido seria de competência do TCU, cuja atuação provisória seria instruída pelo Conselho Nacional de Política Fazendária (CONFAZ).
} 
o acordo, o total de R \$ 65,6 bilhões será distribuído até 2037 (75\% Estados e 25\% Municípios), nos moldes de repartição da Lei Kandir e Fex. Como contrapartida, os entes subnacionais reconhecem a quitação dos valores considerados devidos pela União e suspendem quaisquer ações judiciais para indenização pretérita (Fórum Nacional de Governadores, 2020).

Conforme o rateio previsto pelo acordo, o RS deverá receber $10 \%$ dos recursos, o que equivale a $\mathrm{R} \$ 6,49$ bilhões, sendo que $25 \%$ serão destinados aos municípios. Juntamente com São Paulo, Minas Gerais e Paraná, o estado gaúcho é um dos estados mais beneficiados - fato que é justificado pelo grande peso exportador desses entes. Contudo, em termos financeiros, os ganhos ao RS representam a recuperação de menos de $30 \%$ das perdas líquidas acumuladas historicamente, e os repasses anuais não são suficientes para cobrir o déficit atualmente apresentado pelo estado, que chegou a R\$ 3,2 bilhões em 2019.

Os frutos do acordo, portanto, são muito mais políticos do que financeiros, pois representam o esforço de diálogo dos entes federados mesmo quando interesses diversos estão em jogo, o que fortalece o reequilíbrio do pacto federativo brasileiro. Os reais desdobramentos desse acordo histórico, no entanto, ainda estão por vir, e eventual descumprimento dos prazos ou das condições fixadas poderá levar à retomada da discussão em âmbito judicial. Contudo, já se pode comemorar o respaldo jurídico da reivindicação histórica dos estados com relação à criação de um mecanismo de compensação cuja inexistência ameaça o equilíbrio do pacto federativo, pautado pelo princípio basilar da autonomia de todos os entes federados.

\section{Estimativa dos impactos no orçamento estadual}

Todos os temas abordados nas seções anteriores envolvem as relações políticas intrínsecas ao pacto federativo brasileiro, que busca equilibrar as forças federal, estadual e municipal. Ainda, os três temas impactam - ou, no caso do PNM, tem o potencial de impactar - significativamente as finanças do Rio Grande do Sul. O objetivo da presente seção é juntar os resultados observados e analisar conjuntamente o possível impacto deles sobre o resultado orçamentário entre 2010 e 2014.

O Gráfico 2 abaixo mostra uma trajetória hipotética para os resultados orçamentários do Rio Grande do Sul, ao longo do período 2010-2014, assumindo três hipóteses contrafactuais em conjunto: (a) ausência de perdas do FUNDEB; (b) 
ausência das despesas completivas do piso do magistério; (c) e ausência das perdas líquidas relacionadas à Lei Kandir (com compensações integrais da União).

\section{Gráfico 2 - Resultado orçamentário e impacto estimado dos aspectos analisados (2010-14)}

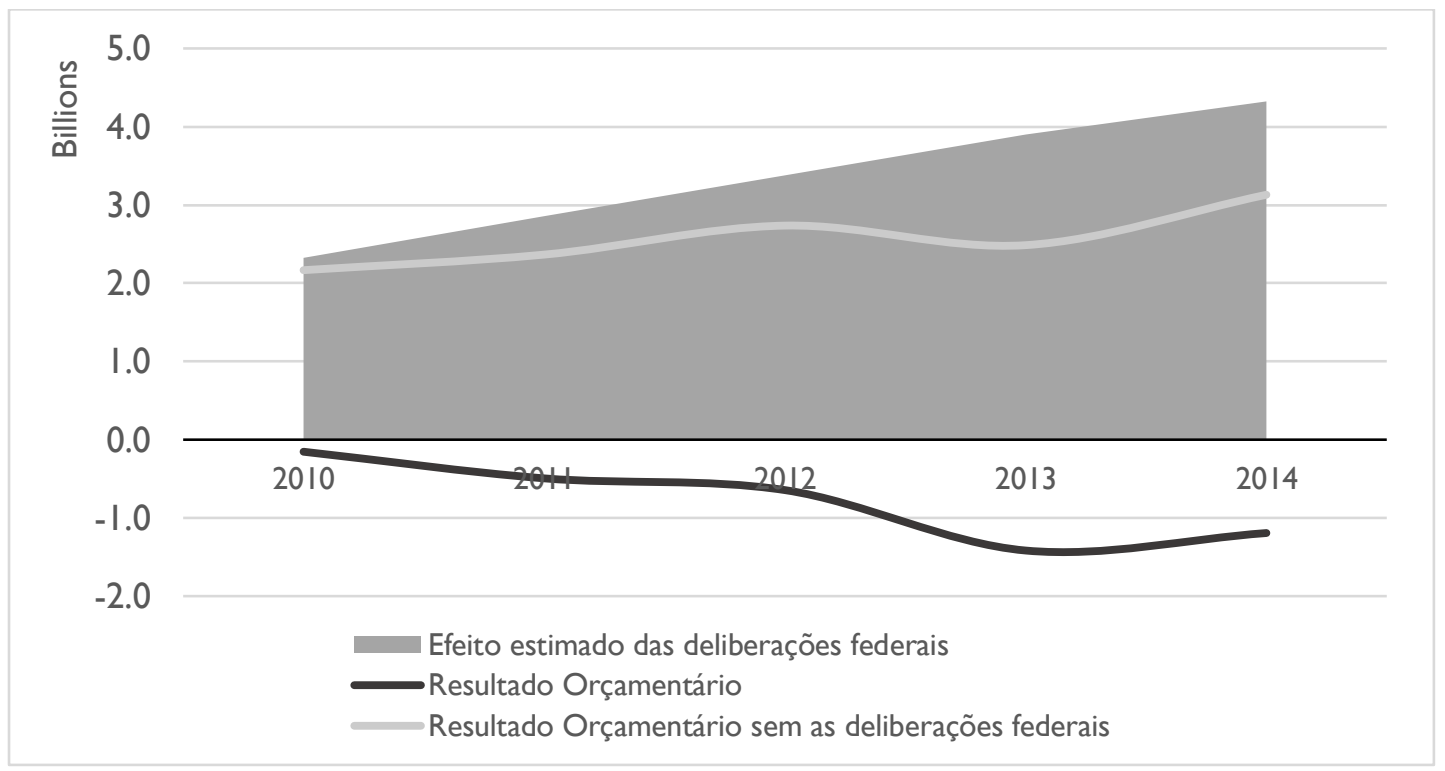

Fonte: elaboração própria a partir dos resultados demonstrados nas tabelas.

Conforme disposto no gráfico, estimou-se que, sem as perdas associadas às deliberações federais, as finanças públicas do Rio Grande do Sul apresentariam superávit durante todo o período analisado, chegando a totalizar mais de $\mathrm{R} \$ 3$ bilhões em 2014.

\section{Considerações finais}

No debate público, não é incomum encontrar referências à situação dos entes públicos subnacionais como estando "falidos" ou "quebrados", analogamente ao que ocorre com as empresas e agentes privados. Conforme já observado na Introdução, encontramos no trabalho da Secretaria do Tesouro Nacional (2018) alguns elementos que fazem alusão a essa analogia, que, na verdade, retrata inadequadamente a situação dos entes públicos federados. Em primeiro lugar, contrariamente ao que é comum no caso de empresas privadas, nem os entes subnacionais nem a União vão simplesmente desaparecer em função de dificuldades para financiar suas atividades e suas despesas. Em segundo lugar, a margem de manobra dos entes subnacionais é algo bastante condicionado por um 
conjunto de regramentos e parâmetros que estão, em grande parte, sujeitos à deliberação em nível federal.

O presente texto propôs-se a ressaltar algumas questões sob esse enfoque, consideradas centrais para o caso do Rio Grande do Sul. Em especial, três aspectos envolvendo deliberações em nível federal impactam efetiva ou potencialmente as finanças públicas estaduais: as regras do FUNDEB, o piso nacional do magistério e as desonerações das exportações trazidas pela LC no 87/1996. Com respeito ao FUNDEB, as perdas de parte do RS em função das regras estabelecidas já totalizam mais de R\$ 9 bilhões desde 2007. Por seu turno, estima-se que uma eventual implementação imediata do piso nacional do magistério tem um potencial de repercussão da ordem de $\mathrm{R} \$$ 5,3 bilhões anuais. Por fim, viu-se que, de 1996 a 2014, a perda líquida total do estado com as desonerações introduzidas pela Lei Kandir chega ao montante de R \$23,3 bilhões.

A projeção realizada pelo Gráfico 2 deve servir sobretudo para ressaltar que os efeitos dos aspectos analisados são extremamente decisivos para o estado geral das finanças públicas estaduais. É impossível saber como teriam sido prestados os serviços públicos no Rio Grande do Sul se o orçamento durante o período de 2010 a 2014 fosse superavitário, dando margem inclusive para maiores investimentos. O que se deve ter em mente é o potencial deletério que muitas decisões tomadas em nível federal têm sobre os resultados fiscais estaduais, agravando muitas vezes acontecimentos sociais e econômicos.

Para além das estimativas quantitativas realizadas, é preciso ficar claro sobretudo que o problema das finanças estaduais será sempre um aspecto específico do pacto federativo mais amplo, ou seja, das condições do equilíbrio de poder entre as unidades subnacionais e a federação. Os três aspectos analisados neste texto são fruto de decisões políticas e como tal devem ser compreendidos.

Desse modo, a continuidade do FUNDEB está em discussão no Congresso Nacional (PEC no 15-A/2015)21 e a manutenção ou alteração das regras atuais dependerão naturalmente das negociações entre os poderes e os entes federados. Por seu turno, a questão de uma efetiva implementação do piso nacional do magistério parece intrinsecamente relacionada à necessidade de lidar com as restrições estabelecidas pela LRF. Com respeito às perdas líquidas decorrentes das

\footnotetext{
${ }^{21} \mathrm{O}$ presente artigo foi submetido para avaliação antes da aprovação do novo FUNDEB ocorrida em 27 de agosto de 2020.
} 
desonerações introduzidas pela Lei Kandir, o recente acordo firmado entre os estados e a União parece representar efetivo avanço de um complexo e moroso processo de negociação; contudo, além de respaldo jurídico para o cumprimento das medidas acordadas, deve-se manter constante vigilância para garantir a efetiva autonomia dos entes subnacionais, sobretudo na questão tributária. Nenhuma dessas questões parece esgotar-se em elementos puramente técnicos, envolvendo necessariamente opções de natureza política.

Defende-se, portanto, o fortalecimento de mecanismos de pesos e contrapesos que fortaleçam o equilíbrio do pacto federativo brasileiro. Assim como no âmbito da União, deve-se buscar uma maior margem discricionária aos entes subnacionais, seja por meio da flexibilização orçamentária, seja pela criação de mecanismos alternativos de financiamento. No caso da questão tributária, especificamente da abordada no presente texto, trata-se de restaurar o equilíbrio, de modo que o mecanismo de compensações pela União aos demais entes federados contrabalance a centralização dos recursos no âmbito da União, trazida pela CF 88.

Por fim, apesar de terem considerável popularidade, a analogia com as firmas da economia convencional parece algo pouco frutífero para avaliar as questões relativas às finanças públicas de entes subnacionais. Certamente os aspectos aqui levantados são mais complexos do que se poderia esgotar neste texto, de modo que o que se pode pretender é apenas demarcar uma posição no debate sobre o federalismo fiscal no Brasil. Um enfoque mais adequado para tal tarefa parece ser aquele que compreende as decisões de cortes superiores como um elemento do sistema de freios e contrapesos institucionais que envolvem o pacto federativo. Decisões judiciais favoráveis aos entes subnacionais têm sido o mecanismo capaz de evitar a descontinuidade de serviços públicos em um quadro geral de baixa discricionariedade sobre receitas e despesas. Um reduzido grau de controle sobre o ambiente jurídico, político e econômico no qual os entes subnacionais se encontram é algo que parece demonstrado por meio de deliberações a nível federal de enormes proporções para as finanças públicas destes entes. 


\section{Referências}

BÓSIO, M. Do desequilíbrio das finanças públicas à crise fiscal do Rio Grande do Sul: uma análise do período 1970-1998. 1999. Dissertação (Mestrado) Universidade Federal do Rio Grande do Sul, Porto Alegre, 1999.

BRASIL. Constituição da República Federativa do Brasil: promulgada em 5 de outubro de 1988. Brasília, 1988. Disponível em: http://www.planalto.gov. br/ccivil_03/constituicao/constitui\%C3\%A7ao.htm. Acessado em: 05/05/2020.

BRASIL. Lei Complementar $n .^{\circ}$ 87, de 13 de setembro de 1996. Dispõe sobre o imposto dos Estados e do Distrito Federal sobre operações relativas à circulação de mercadorias e sobre prestações de serviços de transporte interestadual e intermunicipal e de comunicação, e dá outras providências (Lei Kandir). Disponível em: http://www.planalto.gov.br/ccivil_03/leis/lcp/Lcp87.htm. Acessado em: 05/05/2020.

BRASIL. Emenda Constitucional $n .^{\circ}$ 53, de 19 de dezembro de 2006. Disponível em: http://www.planalto.gov.br/ccivil_03/constituicao/emendas/emc/emc53.htm. Acessado em: 15/08/2019.

BRASIL. Lei Federal n. ${ }^{\circ} 11.494$, de 20 de junho de 2007. Disponível em: http:// www.planalto.gov.br/ccivil_03/_ato2007-2010/2007/lei/111494.htm. Acessado em: 15/08/2019.

BRASIL. Proposta de Emenda Constitucional $n .^{o} 15-A$, de 7 de abril de 2015. Disponível em: http://www.camara.gov.br/proposicoesWeb/fichadetramitacao?id Proposicao=1198512. Acessado em: 15/08/2019.

BRASIL. Ministério da Educação. Resolução $n^{o}$ 1, de 6 de dezembro de 2018. Aprova as ponderações aplicáveis entre diferentes etapas, modalidades e tipos de ensino da educação básica, para vigência no exercício de 2019. Disponível em: https://www.fnde.gov.br/acesso-a-informacao/institucional/legislacao/item/12235 -resolucao-n01,-de-6-de-dezembro-de-2018. Acessado em: 15/08/2019.

CONFEDERAÇÃO NACIONAL DE MUNICÍPIOS. Informativo CNM, fevereiro 2011. Disponível em: https://www.cnm.org.br/cms/biblioteca_antiga/Informativo _2011_Educa\%C3\%A7\%C3\%A3o_2.pdf. Acessado em: 20/09/2019.

FÓRUM NACIONAL DE GOVERNADORES. OFÍCIO 14/20: Termos de Acordo nos Autos da ADO 25, maio de 2020. Disponível em: https://estado.rs.gov.br/upload/arquivos//termos-de-acordo-nos-autos-da-ado-25.pdf. Acessado em: 18/05/2020. 
FRIZZO, M. Os efeitos da Lei Kandir na arrecadação do estado do Rio Grande do Sul no período de 1998 a 2005. In: ENCONTRO DE ECONOMIA GAÚCHA, 4, Porto Alegre: EEG, 2008.

MONTOYA, M.; SOCCOLOSKI, V. Estimativa de perdas de arrecadação de ICMS promovida pela lei Kandir no Corede produção - $R S$ : uma análise sobre as exportações de soja, de 1997 a 2014. Revista Teoria e Evidência Econômica, v. 24, n. 50, p. 51-88, 2018.

PETRY, G.; BRAATZ, J.; MARTINEZ, P. Perspectivas para as finanças públicas do RS no período de 2019 a 2025. Texto para Discussão do Tesouro do Estado do Rio Grande do Sul, n. 10, 2018.

PICOLOTTO, V. Projeções de perda do FUNDEB do governo do RS para o período 2019-2030. Texto para Discussão do Tesouro do Estado do Rio Grande do Sul, n. 12, 2019.

SANTOS, D. Perdas da Lei Kandir, o falso diagnóstico. Disponível em: http://darcyfrancisco.com/wp-content/uploads/2018/

07/Perdas-da-Lei-Kandir-o-falso-diagnóstico.pdf. Acessado em 10/05/2020.

SOARES, M.; MACHADO, J. Federalismo e Políticas Públicas. Brasília: ENAP, 2018.

STN - SECRETARIA DO TESOURO NACIONAL. Exposição da União à Insolvência dos Entes Subnacionais. Texto para Discussão. Brasília-DF, 2018.

SEFAZ-RS. Boletim Informativo de Pessoal. Disponível em: https://tesouro.fazenda.rs.gov.br/upload/1549906517_06\%20DEZ\%20-\%202018 \%20BP\%20Internet.pdf. Acessado em: 10/08/2019.

SEFAZ-RS. Demonstrativo das Desonerações Fiscais do Estado do Rio Grande do Sul. Disponível em: http://www.al.rs.gov.br/FileRepository/repdcp_m505/ CFPFC/Nota\%20Técnica\%20e\%20Demonstrativo\%20Desonerações\%202014.pdf. Acessado em: 10/05/2020.

VARSANO, R. Fazendo e desfazendo a Lei Kandir. Texto para Debate do Banco Interamericano de Desenvolvimento, IDB-DP-304, 2013.

\section{Agradecimentos}

Agradecimento especial a Guilherme Correa Petry, que teve a ideia inicial de concepção deste artigo. 